\title{
Current system of childhood cancer registration in Belarus
}

\author{
Natallia N. Savva, Anna A. Zborovskaya, Olga V. Aleinikova \\ Belarusian Research Center for Pediatric Oncology and Hematology, Minsk, Belarus
}

\begin{abstract}
Background. The purpose of this article is to describe the current system of childhood cancer registration in Belarus and the main principles of organization of Childhood Cancer Sub-registry of Belarus including the retrospective and prospective (formalized and visualized) data collection.

Conclusions. The use of visualized data of the initial diagnostic system not only helps to optimize the prospective recording in the cancer registry, but also contributes to the better verification of individual cases that is sometimes required in the retrospective research and in cases of changes in classification of malignant neoplasm.
\end{abstract}

Key words: cancer registry; children

\section{Introduction}

A high quality population-based cancer registry approved by the government and a recognized international organization is foundational for any epidemiological study and worldwide acceptance of its results. A review of disputable cases by experts is a necessary step for the data input and for the retrospective and for the prospective cancer registry data base verification. The purpose of this article is to describe the current system of childhood cancer registration in Belarus

Paper was presented at the $27^{\text {th }}$ Conference of International Association of Cancer Registries, Ljubljana, Slovenia, 17-20 September 2007.

Received 13 December 2007

Accepted 27 December 2007

Correspondence to: Natallia N. Savva, MD, PhD, Belarusian Research Centre for Paediatric Oncology and Haematology, Ministry of Health of Republic of Belarus, Lesnoe-2, 223040, Minsk region, Belarus; Phone: +375 1726548 61; Fax: +375-17-265-42-22; Email: nsavva@mail.ru,n_savva@yahoo.com and the main principles of organization of Childhood Cancer Sub-registry of Belarus including the retrospective and prospective (formalized and visualized) data collection.

\section{Retrospective data collection}

Previously, there were three main data bases for adult and childhood cancer in Belarus: Belarusian State Cancer Registry within the Belarusian Institute for Medical Technologies, Registry for Hemablastoses within the Research Institute for Hematology and Transfusiology, and Cancer-registry within the Research Institute for Oncology and Medical Radiology. These cancer registries had definite limitations in case verification and registration according to the modern classifications and standards used in childhood oncology.

That is why the Childhood Cancer Subregistry was organized by the Ministry of Health of Belarus in 1999 based at the 
department for clinical and epidemiological research of the Belarusian (National) Research Center for Pediatric Oncology and Hematology (BRCPOH) in Minsk. This Center is responsible for diagnosing and treating all types of malignant neoplasm, except thyroid cancer, in children and adolescents of Belarus (all mentioned categories of patients from the entire country must be diagnosed there and most of them are treated at that Center). This fact contributes to the easier collection and verification of cases for the Childhood Cancer Sub-registry.

The childhood Cancer Sub-registry of Belarus has been undertaking the prospective data collection since the August 1999. As a first step of the retrospective accumulation of cases, the data base for all cancer cases in children $0-14$ years old had been actively collected with the help of the Belarusian State Cancer Registry back to 1989, and verified by the re-examination of slides, disease histories, death certificates etc. with the participation of oncologists, hematologists and cytomorphologists from $\mathrm{BRCPOH}$ and the Research Institute for Oncology and Medical Radiology (Minsk, Belarus). In 2001 the official name 'Childhood Cancer Sub-registry of Belarus', designated and confirmed by certificate, was received (certificate $\# 0170100025$ in the state register of information resources of Belarus, in force from 12.12.2001). The leukemia's part of the automatic data base was subsequently extended back to 1986 with the additional collaboration of the Research Institute for Hematology and Blood Transfusion, which has a prospective database of hemablastosis registered according to the ICD-9 since 1979 and had performed leukemia studies previously published. ${ }^{1-4}$ Since 2004 the Childhood Cancer Sub-registry of Belarus prospectively collects the cancer cases in adolescents (15-19 years old) and extends the data bases for this age retrospectively.

\section{Principles of prospective data organization}

The nationwide Childhood Cancer Sub-registry of Belarus is a computerized system performing previously active data collection that is standardized according to the IARC recommendations ${ }^{5}$ with nearly $100 \%$ level of microscopically verified cancer cases diagnosed after 1990. Its main goal is to register all malignant neoplasm cases in children and adolescents in Belarus with the creation of the maximally verified data base of nosological/morphological forms and continued follow-up events for clinical and epidemiological studies.

The registry staff is divided into a formalized data input group, a visualized data input group, a follow-up group, and a group for technical service and software assistance.

Since the Childhood Cancer Sub-registry of Belarus is located in the BRCPOH (the only national center responsible for childhood cancer in Belarus), every cancer case is entered into the cancer registry immediately after establishing the diagnosis for more than $95 \%$ of cases, and less than 5\% are collected actively during the calendar year.

The following parameters are registered: personal data of patients (names, changed names during the life, passport identification number of a patient or his/her parents, date of birth, address at the diagnosis and other addresses changed during the followup), information about disease (date of disease, date of diagnosis, basis of diagnosis, stage, reference number, date and conclusion of cytomorphological examination, expert's name, the formalized and visualized data of primary diagnostic examinations); information about the treatment and remission status, date and status at follow-up, sources of information, date and cause of death by death certificate; time- and dis- 


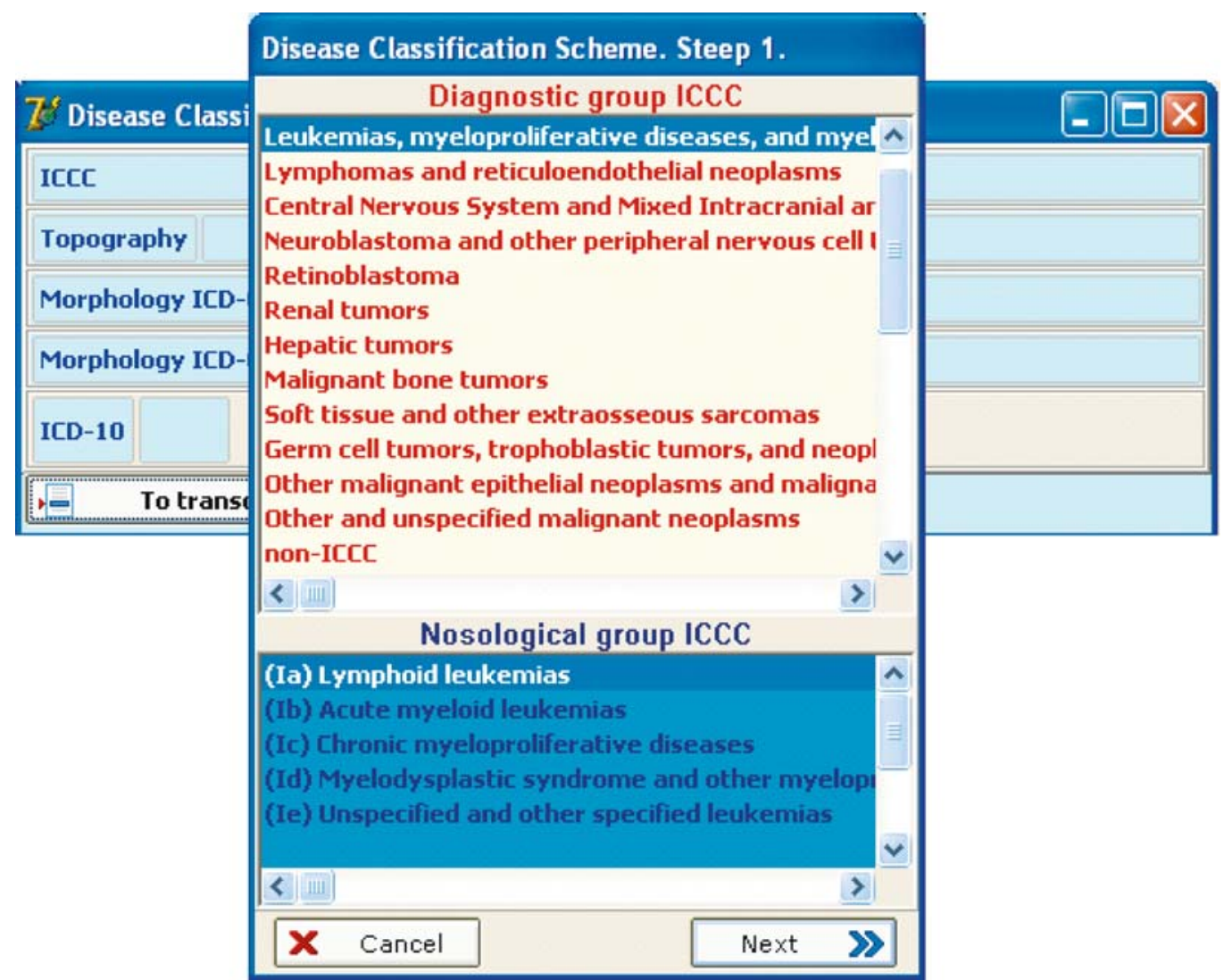

Figure 1. Classification algorithm using in the Childhood Cancer Sub-registry of Belarus.

ease-relation of malignances (de novo, secondary, or multiple primaries). All cancer cases are coded according to ICCC $-3^{6}$ and ICD-O-3 (morphology and topography), and converted automatically to ICD-O-2 and ICD-10 (Figure 1).

The sources of primary information are the following: hematological departments of regional clinics, hematological consultations, oncological dispensaries, specialized clinics, autopsy units and morphological laboratories. As the filling of the information about the primary established/suspected cancer cases and cancer deaths to Belarusian State Cancer Registry is mandatory for all medical institutions in Belarus, the Childhood Cancer Sub-registry of Belarus fulfils the annual verification of its database with the Belarusian State Cancer Registry using codes ICD-O-2 and ICD-10. Additionally, the Childhood Cancer Subregistry of Belarus verifies its data base on an ongoing basis with the clinical registries organized in BRCPOH for every nosological group and treatment protocol.

Since 2004, the database of the Childhood Cancer Sub-registry has been also prospectively populated with the visualized data of morphological, immunological, cytogenetic and molecular-biological methods as well as computer tomography (CT) and ultrasound (US) examinations for the prospective and retrospective verification of cancer cases due to the creation of the computeraided system for the registration and accumulation of the visualized and formalized 


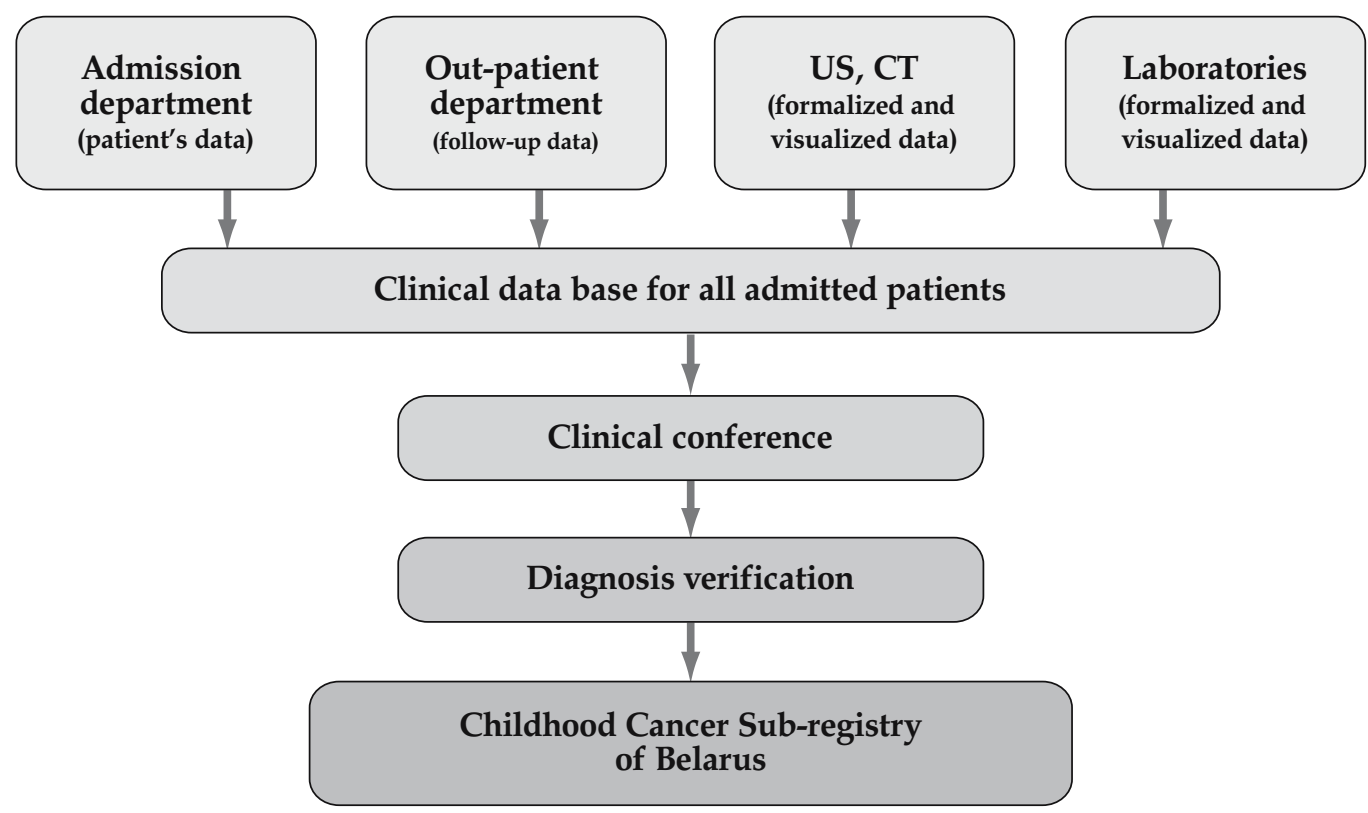

Figure 2. The information flows into the Childhood Cancer Sub-registry realized with help of the computer-aided system for formalized and visualized data of the primary diagnostic complex for patients with cancer inside the Belarusian Research Center for Pediatric Oncology and Hematology.

data of the primary diagnostic complex for patients with cancer. ${ }^{7,8}$ This system includes the Clinical Base for Visualized and Formalized Data, where all information is accumulated from the automated (computer-aided) doctor's workplaces located in different laboratories (cytological, morphological, immunological, cytogenetical and molecular genetical) and in the departments for US and X-ray/CT diagnostics. The system of the data visualization also enables us to provide the distant consulting services as well as the weekly clinical conferences where all primary cancer cases are discussed before the input into the data base of the cancer registry (Figure 2).

The short-term (within the first five years after the end of the anti-cancer treatment) and the long-term follow-up is implemented by active (including expeditions) and passive monitoring using the sources of the out-patient department of BRCPOH (information goes automatically into the registry data base), the Belarusian State Cancer Registry, autopsy units and morphological laboratories, medical institutions (clinics and territorial policlinics), registry offices and hospices. The short-term follow-up requires the update of the case's status as minimum as once a year, and long-term - as minimum as once a two years; and the registry's software alarms the necessity of updating and generates a list of cases.

The system enables automatic calculation of incidence (crude, TASR - word and euro standard), overall survival and mortality rates for various nosological groups, ages, regions, and provides TERSON-code maps.

The patient information and consent to registration and continued follow-up are requested to be signed at the time the personalized data are entered into the Childhood Cancer Sub-registry database. 


\section{Conclusions}

Timely and quality recording of childhood cancer at the national level and accumulation of verified information in the database of the automatic cancer registry not only supports a long-term epidemiologic and clinical research, but also enables experts to quickly obtain data on incidence, survival and death rate for a given span and undertake a prompt analysis of the existing trends, e.g. at request of the Ministry of Health for planning future action. In our opinion, the use of visualized data of the initial diagnostic system not only helps to optimize the prospective recording in the cancer registry, but also contributes to the better verification of individual cases that is sometimes required in the retrospective research and in cases of changes in classification of malignant neoplasm.

\section{Acknowledgements}

The programs for visualization of primary diagnostic complex and code-converting were created by specialists of United Institute for Informatics Problems of National Academy of Science of Belarus with the support of International Scientific Technical Center, (Project B-736, http:// tech-db.istc.ru/ISTC/sc.nsf/html/projectsall-by-number.htm?open\&start=B).

\section{References}

1. Ivanov E, Tolochko G, Lazarev V, Shuvaeva L. Child leukemia after Chernobyl (Scientific correspondence). Nature 1993; 365: 702.

2. Ivanov E, Tolochko G, Shuvaeva L, Becker S, Nekolla E, Kellerer A. Childhood leukemia in Belarus before and after the Chernobyl accident. Radiat Environ Biophys 1996; 35: 75-80.

3. Gapanovich V, Iaroshevich R, Shuvaeva L, Becker S, Nekolla E, Kellerer A. Childhood leukemia in Belarus before and after the Chernobyl accident: continued follow-up. Radiat Environ Biophys 2001; 40: 259-67.

4. Ivanov E, Tolochko G, Shuvaeva L, Ivanov V, Iaroshevich R, Becker S, et al. Infant leukemia in Belarus after the Chernobyl accident. Radiat Environ Biophys 1998; 37: 53-5.

5. IARC Scientific Publication No.95. In: Jensen OM, Parkin DM, MacLennan R, Muir CS, Skeet RG, editors. Cancer registration: principles and methods; 1991.

6. Steliarova-Foucher E, Stiller C, Lacour B, Kaatsch $P$. International classification of childhood cancer. Third edition. Cancer 2005; 103: 1457-67.

7. Khristich GA, Savva NN, Bydanov OI, Sergeev EA, Aleinikova OV, Anishchanka UV, et al. Computeraided system for registration of formalized and visualized data for the primary diagnostic complex of the malignant neoplasm. In: Anishchanka UV, editor. Proceeding of the International Conference "Advanced information and telemedicine technologies for health, AITTH'2005". Minsk: UIIP; 2005. Vol. 2. p. 177-83.

8. Savva NN, Bydanov OI, Sergeev EA, Aleinikova OV, Anishchanka VV, Khristich GA. Computeraided system for registration of the formalized and visualized data of patients, represented as one of the childhood cancer-register operation chains (abstract). In: Program and book of abstracts. Euroregional Conference on "Building Information Society in the Healthcare in Euroregion Niemen". Bialystok; 2005. p. 53-4. 